BNL 50805

UC-28

(Particle Accelerators and

High-Voltage Machines - TID 4500)

\title{
PROPOSAL FOR A BOOSTER TO RAISE THE INJECTION
}

ENERGY OF THE AGS

T. F. Kycia and M. Month

February 14, 1978

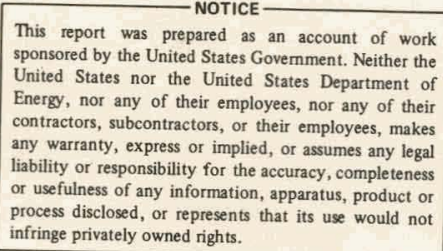

process disclosed, or represents that its use would not
infringe privately owned rights.

ACCELERATOR DEPARTMENT

B R O O K H A V E N N A T I ONA L LA B.O RA TOR T

A S S O C I A T E D UN I VER S I T I E S, I N C.

U P T O N, N E W Y O R K 11973

under contract No. EY-76-C-02-0016 with the 


\section{DISCLAIMER}

This report was prepared as an account of work sponsored by an agency of the United States Government. Neither the United States Government nor any agency Thereof, nor any of their employees, makes any warranty, express or implied, or assumes any legal liability or responsibility for the accuracy, completeness, or usefulness of any information, apparatus, product, or process disclosed, or represents that its use would not infringe privately owned rights. Reference herein to any specific commercial product, process, or service by trade name, trademark, manufacturer, or otherwise does not necessarily constitute or imply its endorsement, recommendation, or favoring by the United States Government or any agency thereof. The views and opinions of authors expressed herein do not necessarily state or reflect those of the United States Government or any agency thereof. 


\section{DISCLAIMER}

Portions of this document may be illegible in electronic image products. Images are produced from the best available original document. 
This report was prepared as an account of work sponsored by the United States Government. Neither the U.S. nor the U.S. Department of Energy, nor any of their employees, nor any of their contractors, subcontractors, or their employees, makes any warranty, express or implied, or assumes any legal liability or responsibility for the accuracy, completeness or usefulness of any information, apparatus, product or process disclosed, or represents that its use would not infringe privately owned rights.

PRINTED IN THE UNITED STATES OF AMERICA Available from

National Technical Information Service

U.S. Department of Commerce 5285 Port Royal Road Springfield, VA 22161

Price: Printed Copy $\$ 4.00$ ; Microfiche $\$ 3.00$ 


\section{ABS TRACT}

A proposal to insert a small circumference, energy booster between the $200 \mathrm{MeV}$ Linac and the AGS is presented. The possible increase in AGS performance is pointed out. In particular, one can expect an increase in protons on target for the $\nu$ program, an increase in $\vec{p}$ flux, an increase in AGS operational reliability and an increase in beam brightness for ISABELLE.. In addition, and perhaps most significantly, it could allow rapid current accumulation for ISABELLE with reduced aperture requirement, avoiding altogether the complexities associated with the present rf stacking approach. It is suggested that the existing PPA accelerator can serve as an ideal booster for the AGS complex. Furthermore, this machine is presently available intact. To obtain high brightness beams as well as intense beams, it appears to be necessary to shift to $\mathrm{H}^{-}$injection from the Linac to the Booster. In this way, it is conceivable that $\sim 10^{14}$ protons per AGS pulse could become a reality. In such an operating mode, extensive rf and shielding modifications would undoubtedly be required. It also appears that AGS beam dumps would become necessary. ISABELLE performance is considered. A possible scenario suggests a bunched beam average luminosity reaching almost $10^{33} \mathrm{~cm}^{-2} \mathrm{sec}^{-1}$. If debunched, this would fall to $\sim 10^{32} \mathrm{~cm}^{-2} \mathrm{sec}^{-1}$. Also, the simplicity and speed of the proposed operational mode suggests that such performance is in principle the "day-1-performance". 
It is proposed to insert a sma11, energy booster ${ }^{*}$ (circumference $\sim 1 / 10$ of the AGS circumference) between the $200 \mathrm{MeV}$ Linac and the AGS. As a consequence of such an addition to the AGS complex, there would result a remarkable increase in the performance potential of the AGS: (1) The rate of protons on target could be increased by at least a factor of four leading, for example, to a dramatic improvement in the $\nu$ program. (2) The $\bar{p}$ production rate would rise significantly, with the increased $\bar{p}$ flux serving a variety of purposes for high energy physics. (3) The AGS would become capable of producing high brightness beams, greatly enhancing the quality of the beams for ISABELLE. Specifically, one might consider the acceleration of $\geqslant 4 \times 10^{13}$ protons per AGS pulse (or, $>3 \times 10^{12}$ per AGS bunch) in the low emittance, $E \leqslant 10 \pi \mu \mathrm{rad}-\mathrm{m}$. (4) The new system would open the possibility of a high performance ISABELLE with rapid boxcar stacking. Each ISABELLE ring could actually be filled in the remarkably. low time of $\sim 10 \mathrm{sec}$. Furthermore, al1 special "rf manipulation" in ISABELLE, such as rf stacking, rebunching, debunching could be avoided. The beam aperture requirement would be greatly reduced from the present ISABELLE design and the tolerable longitudinal impedance substantially weakened. In addition, a11 nonhalo-type beam scraping in ISABELLE would become unnecessary. (5) Although the new AGS system would allow bright as well as intense beams, the initial production of such beams is not trivial. A simple solution is the use of low current $\mathrm{H}^{-}$beams $(\sim 1 \mathrm{~mA})$ to stack high current in the Booster at $200 \mathrm{MeV}$. A dividend of such a simple injection procedure is an increase in AGS reliability, for example, in turning on the AGS after a maintenance period or shutdown.

\footnotetext{
"The idea of using a booster for the AGS is not new. In particular, a $1 \mathrm{GeV}$ booster was proposed by: M. Q. Barton, J. P. Blewett, E. D. Courant, A. W. Maschke, I. Polk, J. Spiro and G. W. Wheeler in Report AADD-127, "Design Study for a 1000-MeV Booster Synchrotron Injector for the Brookhaven AGS" (1966), to operate with the old $50 \mathrm{MeV}$ Linac. However, a $4 \mathrm{GeV} / \mathrm{c}$ fast-cycling booster for the AGS is actually quite a novel suggestion.
} 
To achieve such goals, one might consider the following type of procedure:

- Accelerate a low current $\mathrm{H}^{-}$. beam $(\sim 1-10 \mathrm{~mA})$ in the Linac to its peak kinetic energy of $200 \mathrm{MeV}$.

- Accumulate a long Linac pulse $(\geqslant 500-50 \mu \mathrm{sec})$ in the Booster $\left(>3 \times 10^{12}\right.$ protons) by charge exchange injection.

- Accelerate a single bunch in the Booster to a total energy of $4 \mathrm{GeV}$. With a rapid cycling Booster this could be accomplished in $\sim 1 / 20$ second.

- Transfer the single bunch from the Booster to the AGS and repeat the process 12 times accumulating 12 bunches. in the AGS $\left(\geq 4 \times 10^{13}\right.$. protons) in $\sim \frac{1}{2}$ second.

- Accelerate the 12 bunches in the AGS to $30 \mathrm{GeV}$ with a rise time of $\sim \frac{3}{2}$ second.

- With this procedure, the proton production rate is $\geqslant 4 \times 10^{13}$ protons in $\sim 1 \frac{1}{2} \mathrm{sec}$ (AGS complete cycle time); that is, $\geqslant 4 \times 10^{13} \mathrm{ppp}$.

There are, of course, many options open in choosing a booster type. However, some consideration has led us to the conclusion that a weak focusing lattice has several unique advantages: The low gradient allows for a simple magnet system which can produce good field over a wide aperture as well as high magnetic fields and, in addition, rapid cycling at a rate of 20 per second can be attained. The high field allows the inclusion of sufficiently long straight sections necessary for a variety of equipment, including rf stations and extraction hardware at $p \approx 4 \mathrm{GeV} / \mathrm{c}$. Various aspects of the weak focusing structure are especially useful for the energy range of interest; $200 \mathrm{MeV}$ to $\sim 3 \mathrm{GeV}$ kinetic energy. Since injection takes place above the transition energy, no transition crossing is necessary. The negative mass instability is overcome by injecting a beam with sufficient energy spread. This can be achieved by a small modulation of the energy of the long $\mathrm{H}^{-}$pulse injected. A corresponding field modulation in the booster avoids any horizontal emittance increase. The large dispersion function characteristic of weak focusing machines coupled with the momentum spread required to 
avoid the negative mass effect results in a typically "thick, ribbon beam". This is an optimum configuration, fitting with the magnet aperture which is also typically large in width and rather smaller in height $(7.5 \mathrm{~cm} \mathrm{~V} \times 25 \mathrm{~cm} \mathrm{H})$. The optimization goes somewhat further than just a geometric fit. For a given intensity, this beam shape tends to minimize transverse space-charge effects. In particular, the space-charge tune shift is not too high $(\Delta \nu<0.2)$ and coherent transverse instabilities (e.g., the resistive wall) are manageable.

These considerations have prompted us to ask whether the existing PPA (Princeton-Penn Accelerator) might be suitable for the purposes described. The fact is that the booster characteristics that are desired are almost indistinguishable from those of the PPA. The PPA seems to be an ideal machine. Its availability makes the situation almost too good to be true. There are two areas where some change in the PPA structure will be required. In the first place the booster rf must operate at the 1st harmonic of the revolution frequency. This means a relatively small frequency range, $\sim 2.2 \mathrm{MHz}$ (at $200 \mathrm{MeV}$ ) to $\sim 3.8 \mathrm{MHz}$ (at $\mathrm{p} \approx 4 \mathrm{GeV} / \mathrm{c}$ ). With a $75 \mathrm{kV}$ peak voltage, this $\mathrm{rf}$ system might not be too complicated. However, because of the high intensity, $>4 \times 10^{12} \mathrm{ppp}$ (which becomes possible because of the combination of $\mathrm{H}^{-}$injection and the easing of space-charge effects at the high injection energy of $200 \mathrm{MeV}$ ), beam loading could become a significant consideration in the design of a new PPA rf system. Alșo, an increase in PPA intensity by more than an order-of-magnitude (from $\sim 10^{11}$ ppp to $\sim 4-8 \times 10^{12}$ ppp) necessitates a careful check to establish the new shielding requirements and whether existing machine equipment and hardware can tolerate the higher intensity.

The insertion of a $4 \mathrm{GeV}$ booster between the Linac and the AGS has a variety of implications for the latter. The higher energy injection means that the magnets would not require low field operation: At $\sim 4 \mathrm{GeV}$, the required AGS field is $\sim 1.5 \mathrm{kG}$. Injection into the AGS would be direct synchronous transfer of bunches from the booster. Thus, the large injection losses characteristic of present AGS operation would be 
eliminated. When operating the AGS at intensities significantly higher than at present, one might ask about the question of transition crossing. However, by longitudinal density dilution, the crossing conditions can be made equivalent (the actual longitudinal density is higher in the high intensity situation). On the other hand, if even higher densities are desired, special quadrupoles for a transition-y-jump could be installed in the AGS. The CERN PS operates routinely in this way. At the highest intensities that we can conceive $\left(\sim 10^{14}\right.$ ppp in the AGS), the rf system would have to function under extreme beain loading conditions (that is, the beam power required at peak ramp rate $>>$ cavity power loss). Extensive modifications in the rf system would, therefore, be necessary. The cavities themselves might be adequate; however, to avoid the "Robinson Instability" they would have to operate largely detuned from resonance. Thus, much larger power tubes would be required to deal with the increased reactive power. Another aspect of operating the AGS at greatly increased intensity is the question of particle loss and the resulting radiation. Clearly, particle loss will have to be controlled at a much higher level than at present. Radiation resistant hardware will have to replace much of the existing hardware. It also seems likely that both internal and external beam dumps will be required.

The implications for ISABELLE of high brightness, high intensity beams produced by the AGS complex are far reaching indeed. Consider the following possible scenario: Take $7 \times 10^{12}$ protons per PPA pulse. This could provide 60 such bunches in each ISABELLE ring in less than 10 seconds. (To avoid beam loading in the AGS, one could consider accelerating one bunch at a time, thus increasing the filling time per ISABELLE ring to 1.5 minutes.) with $4.2 \times 10^{14}$ protons in ISABELLE (circumference is $5 \times$ AGS circumference), we have an average current of $5 \mathrm{~A}$. Now, keep in mind that the stacking is simple boxcar, with kicker rise times $\sim 180 \mathrm{nsec}$, that aperture utilization $\sim 2 \mathrm{~cm}$, and beam separation is obtained by control of the relative rf phase of the two ISABELLE rings. The simplicity and speed of the ISABELLE filling, , the lack of rf manipulation such as rebunching and debunching, the 
simplicity of bringing the beams into collision, and the small magnet aperture utilization all lead to the probability of high performance, reliable day-one operation. With bunched beams, with the assumed parameters, we can expect to achieve an average luminosity of almost $10^{33} \mathrm{~cm}^{-2} \mathrm{sec}^{-1}$ at $400 \mathrm{GeV}$. In the case of debunched operation, the beams accumulated as above will provide a luminosity in excess of $\sim 10^{32} \mathrm{~cm}^{-2} \mathrm{sec}^{-1}$ at $400 \mathrm{GeV}$. We remark that these performance figures apply for the standard insertion.

A preliminary consideration of some of the details of the proposal given here indicates that the implementation of such a project is indeed feasible. Depending on the level of performance chosen, the cost should be in the range $\$ 5-15 \mathrm{M}$.

In summary, the incorporation of the PPA accelerator as an injection energy booster for the AGS would provide: the potential for a great increase in the performance both of the AGS program and the ISABELLE Project. 